\title{
POMEN OKOLJSKE OZAVEŠČENOSTI IN SODELOVANJA JAVNOSTI ZA TRAJNOSTNI RAZVOJ
}

\author{
Metka Špes \\ Oddelek za geografijo Filozofske fakultete Univerze v Ljubljani, Aškerčeva 2, \\ SI - 1000 Ljubljana, Slovenija. \\ e-mail: metka.spes@ff.uni-lj.si
}

Izvirni znanstveni članek

COBISS 1.01

\section{Izvleček}

Pri trajnostnem razvoju, ki zahteva uravnoteženost med ekonomskimi, socialnimi in okoljskimi cilji, je ključnega pomen tudi najširša udeležba javnosti. Za poznavanje ekoloških in razvojnih odločitev pa je potrebno zagotoviti objektivne informacije in dvig splošne okoljske zavesti. Posameznik ali skupine ljudi bodo reakcije na negativne pojave v okolju gradili na njegovi percepciji, ki pa ne ustreza vedno objektivnemu stanju, ampak ga modificirajo različni dejavniki, med njimi tudi dostop do informacij in sodelovanje javnosti pri odločanju.

Ključne besede: trajnostni razvoj, okoljska zavest, sodelovanje javnosti, percepcija ekoloških problemov

\section{THE IMPORTANCE OF ENVIRONMENTAL AWARENESS AND PUBLIC PARTICIPATION FOR SUSTAINABLE DEVELOPMENT}

\begin{abstract}
In sustainable development which requires the balance between the economic, social and environmental objectives, it is of key importance that the public also participates in the broadest sense. For the comprehension of ecological and developmental decisions it is necessary to provide information and to raise the general environmental awareness. An individual or groups of people base their reactions to negative phenomena in the environment on their perception of it, which does not always correspond to the objective state but is modified by different factors, also by the access to information and by the participation of the public in taking the decisions.
\end{abstract}

Key words: sustainable development, environmental awareness, participation of public, perception of ecological problems 


\section{UVOD}

Za uresničevanje načel trajnostnega razvoja je ključnega pomena široka udeležba javnosti, kjer mora posameznik oziroma različne skupine prebivalstva poznati in razumeti stanje okolja in pomen njegovega varovanja, morajo pa tudi sodelovati pri okoljskih in razvojnih odločitvah. Tovrstno razumevanje in reakcije pa so odvisne predvsem od njihove percepcije okolja oziroma od njihov okoljske ozaveščenosti. Danes skoraj ni mogoče najti razvojnega ali okoljevarstvenega dokumenta, ki ne bi temeljilo na paradigmi trajnosti. Večkrat so njegove razlage ali implementacije $\mathrm{v}$ prakso prilagojene le trenutnim potrebam in pogosto tudi neskladne z osnovno idejo trajnosti. Za izvorni dokument, ki opredeljuje pomen trajnostnega razvoja štejemo t.im. Brundtlandino poročilo z naslovom Our Common Future, ki ga je leta 1987 pripravila Svetovna komisija za okoljski razvoj. V njem je trajnostni razvoj razložen kot » proces sprememb, kjer je izkoriščanje naravnih virov, usmerjanje investicij, tehnološkega napredka in institucionalnih sprememb skladno tako s sedanjimi kot prihodnjimi potrebami« ali bolj preprosto, to je »razvoj, ki zadošča današnjim potrebam, ne da bi pri tem ogrožal možnosti prihodnjih generacij, da te zadostijo svojim lastnim potrebam«.

Pomembno je spoznanje in zavedanje, da doseganje trajnosti ni končni cilj, ampak je to uravnotežen in prilagodljiv evolucijski proces nenehnega iskanja ravnovesja med materialnim blagostanjem, socialno varnostjo in zdravim okoljem. Pri doseganju teh ciljev pa je ključnega pomena tudi okoljsko ozaveščanje oziroma krepitev zavesti o odgovornosti posameznika za stanje v okolju in vzpodbujanje pripravljenosti za spreminjanje osebnih vrednot.

Agenda 21, dokument, ki definira trajnostni razvoj in je obenem akcijski načrt za njegovo uresničevanje, je bil sprejet na svetovni konferenci o okolju v Riu de Janeiru (1992), poudarja, da so pomembna načela trajnostne družbe:

- $\quad$ spoštovanje življenja in odgovornost zanj

- $\quad$ izboljševanje kakovosti človekovega življenja

- ohranjanje vitalnosti in pestrosti narave

- zmanjšanje izčrpavanja neobnovljivih virov

- upoštevanje nosilne zmogljivosti (potenciala, občutljivosti, samočistilnih, regeneracijskih sposobnosti) okolja

- $\quad$ spreminjanje osebnega odnosa in ravnanja

- usposabljanje skupnosti za odgovorno ravnanje z okoljem (Agenda 21 za Slovenijo, 1995).

Na podlagi ekološke zavesti in percepcije okolja oblikuje posameznik, skupina ljudi in končno tudi družba odnos do okolja in do aktualnih ekoloških problemov v ožjem bivalnem okolju pa tudi širše. Vendar pa ta odnos in odzivi na posledice lastnega delovanja ne ustrezajo vselej dejanskemu stanju in obsegu pokrajinskih učinkov človekovih posegov. Ugotavljamo, da ekološka zavest pomembno vpliva na kakovost in obseg teh reakcij. Zato je ena od ključnih nalog »trajnostne družbe«, da omogoča dostop do objektivnih informacij, da zagotavlja udeležbo javnosti pri odločanju in s tem pomaga dvigovati okoljsko zavest ter spreminjati navade in aktivnosti, ki imajo negativne vplive na okolje. Kirn (2003) ugotavlja, da je ozaveščenost o lastni soudeležbi pri nastajanju okoljskih posledic, elementarni pogoj, da človek spremeni vzorce svojega ravnanja. 


\section{ODZIVI NA ONESNAŽEVANJE OKOLJA}

Že iz preteklosti poznamo primere, ko je ob prekomerni onesnaženosti, hrupu, smradu, prihajalo do različnih reakcij ljudi na te neprijetnosti. $\mathrm{O}$ antični, rimski zakonodaji lahko rečemo, da je bila v nekaterih delih "ekološko naravnana". Na primer: za gradnjo črpališč pitne vode in njeno napeljavo je bilo treba pridobiti posebna cesarjeva dovoljenja, da ne bi prišlo do njene nesmotrne rabe; nedopustno je bilo, da bi na primer smrad iz sirarn motil sosede; odpadne vode je bilo prepovedano zlivati iz stanovanj ali celo odmetavati odpadke. V srednjeveškem Londonu so na primer že v 13. stoletju omejevali uporabo premoga, kovačem so predpisali čas, ko so premog lahko kurili v svojih pečeh, znamenje dobrega obnašanja $\mathrm{v}$ soseski je bila tudi omejena uporaba hrupnih kladiv. Posebna nadloga tedanjih Londončanov so bile velike količine smeti. Pisatelj Evelyn je zapisal, da umazano in zasmeteno mesto spominja na predmestje pekla. Odpadke so pogosto odlagali v reko in v zgodovinskih virih je mogoče razbrati, da so se menihi, ki so imeli mlin niže ob reki, pogosto pritoževali, da jim odpadki, ki jih reka prinaša iz Londona, lomijo mlinska kolesa (Brimlecombe, Nicholas, 1993).

Poznamo tudi domače, slovenske primere, ko so ljudje že zelo zgodaj opozarjali na posledice onesnaževanja okolja. Avstrijska vlada je leta 1873 v Celju dala zgraditi državno cinkarno. Po prvotnih načrtih naj bi industrijski obrat zgradili v Rimskih Toplicah, kjer je nekoč že stala manjša topilnica cinka. Takratni lastnik toplic pa se je tej zamisli odločno uprl, ker se je, kot je razvidno iz arhivov, zavedal nevarnosti škodljivih vplivov onesnaženega zraka. Zato so cinkarno zgradili v Celju, pri pogodbi o načrtovani gradnji pa je tudi določilo: "Ako bi prišle na vrsto naprave, ki bi mogle biti zdravju škodljive, bo o njih odločala posebna komisija.” Že v začetku 30. let prejšnjega stoletja so opozarjali, da tovarniški plini povzročajo precejšnjo škodo na rastlinah. Iz tega časa je dokument, da so opazili negativne učinke na poljščinah, gozdarji pa so ugotavljali škodo na gozdovih. Zavodu za agrikulturno kemijo v Zagrebu so leta 1933 poslali vzorce drevesnih listov in analiza je pokazala, da je v njih precej Žvepla (Orožen, 1974).

Slovenija ima razmeroma dolgo tradicijo na področju javnega ozaveščanja v odnosu do okolja, kjer so v preteklosti pomembno vlogo odigrala nekatera društva, kot npr. planinsko, taborniško, prirodoslovno itd. Že leta 1972, ko je bila v Stockholmu prva konferenca OZN o okolju, je pri nas izšla Zelena knjiga s strokovnimi prispevki, ki so opozarjali na potrebe po spremenjenem odnosu do okolja. Na pobudo Skupnosti za varstvo okolja je bila isto leto ustanovljena še Komisija Skupščine SRS za okolje z namenom, da bi vplivala na formiranje politike varstva okolja in realizacijo konceptov njegove zaščite. Tri leta kasneje pa bil v okviru Izvršnega sveta Skupščine ustanovljen še Republiško komite za varstvo okolja. Za predhodnika civilnih gibanj na tem področju gre šteti Svet za varstvo okolja, aktivnejšo vlogo pa je kasneje prevzela Zveza društev za varstvo okolja, ki je združevala in koordinirala aktivnosti lokalnih društev. Povezovala in združevala je ekološko ozaveščene posameznike, ki so pri svojih aktivnosti vzore iskali pri t.im. zelenih gibanjih v Zahodni Evropi, predvsem v Nemčiji. Leta 1989 je bilo pripravljeno prvo kompleksno poročilo o stanju okolja v Sloveniji. Poldrugo desetletje po izidu Zelene knjige o ogroženosti okolja v Sloveniji, je Svet za proučevanje in varstvo okolja pri SAZU izdal obsežen zbornik Slovenija 88 -okolje in razvoj 
s prispevki več kot 40 strokovnjakov, ki so osvetlili široko paleto okoljskih sprememb, predvsem pa so poskušali javnost opozoriti na naraščajoče ekološke probleme.

Prvi slovenski zakon o varstvu okolja je bil sprejet leta 1993, le leto po konferenci o okolju v Riu de Janeiru, zato že vključuje spoznanja in priporočila iz dokumentov, ki so bili sprejeti na tej konferenci. Izhaja iz ugotovitve, da varstvo okolja ni zgolj ali predvsem čiščenje onesnaženega okolja, ampak pridobiva na pomenu preventivno ravnanje ter pretehtano obnašanje pri odločitvah za nove posege $\mathrm{v}$ okolje in izkoriščanje naravnih virov. Med pomembnejšimi temeljnimi načela zakona velja izpostaviti načelo celovitosti, ki izhaja iz spoznanja, da varstvo okolja ni možno uspešno urejevati parcialno in brez konsenza ter sodelovanja. Za preprečevanje okoljske škode in objektivno presojo posegov je zakon izpostavil tudi načelo javnosti podatkov in postopkov na področju varstva okolja (Zakon o varstvu okolja, 1993). Zakon uvaja še obveznost, da ministrstvo vsako letno pripravi poročilo o stanju okolja in ga po sprejetju v Državnem zboru tudi javno objavi. Skladno s tem je bilo prvo poročilo o stanju okolja pripravljeno in objavljeno že leta 1995 in je temeljilo na uveljavljenem konceptu poročanja »stanje-pritiski-odgovori«.

Zahteve po uskladitvi zakonodaje $\mathrm{z}$ evropsko in nekatere težave pri implementaciji prejšnjega zakona, so leta 2004 sprožile sprejetje novega zakona o varstvu okolja. Pri njegovih osnovnih ciljih, namenih in načelih je tokrat še bolj poudarjena zahteva po upoštevanju trajnostnih načel in, na podlagi zahtev Aarhuške konvencije, tudi o dostopu do informacij in udeležbi javnosti pri odločanju. Glede na ta zakon (2004) je resorno ministrstvo dolžno vsaki dve leti poročati o stanju okolju v obliki kazalcev. Poročili za leti 2003 in 2005 obravnavata 51 oziroma 59 okoljskih kazalcev primerljivih s tistimi, ki jih uporablja Evropska agencija za okolje. Razvrščeni so v vsebinske sklope in razdelani v nizih, ki omogočajo njihovo presojo ter vsebinsko in kronološko primerljivost.

Leta 1998 je Slovenija potrdila tudi prvi nacionalni program varstva okolja, katerega cilji so: izboljšanje stanja vodnega okolja, uveljavitev sodobnih oblik ravnanja z odpadki, ohranitev biotske raznovrstnosti ter krepitev inštitucij varstva okolja na vseh ravneh. Program izhaja iz ocen stanja sestavin okolja in napoveduje ukrepe za njihovo izboljšanje ali ohranitev. Za najbolj ranljive ekosisteme: kras, gorska območja in obalo predlaga poudarjeno skrbne strokovne presoje predvidenih posegov (MOP, 1998).

Skladno s spremenjenim zakonom, $\mathrm{z}$ okoljskim programom EU ter $\mathrm{z}$ namenom upoštevati priporočila, ki so bila sprejeta na svetovni konferenci o trajnostnem razvoju $\mathrm{v}$ Johannesburgu, je bila 2005. pripravljena nova resolucija o nacionalnem programu varstva okolja do leta 2012. Med prednostnimi cilji še naprej ostajajo narava in biotska raznovrstnost ter odpadki, za razliko od prvega programa pa so izpostavljene še podnebne spremembe, kakovost življenja in industrijsko onesnaževanje. Tokratna resolucija izpostavlja še pomen nevladnih okoljskih organizacij kot pomembnih akterjev pri reševanju okoljskih problemov (MOP, 2005).

\section{KAKO SE OBLIKUJE OKOLJSKA ZAVEST?}

Med pomembne ukrepe za doseganje ciljev trajnostnega razvoja sodi okoljsko ozaveščanje oziroma krepitev zavesti o lastni odgovornosti, kar je tudi pogoj za spreminjan- 
je vrednot, vzorcev obnašanja in življenjskega sloga. Pogosto se dogaja, da premagovanje ekoloških problemov ni le tehnološko ali strokovno vprašanje, temveč je odvisno tudi od načina in stopnje njihovega razumevanja. Gold (1980) meni, da se elementi in procesi, ki vplivajo na razumevanje okolja, delijo v tri kategorije: spoznavne procese, ki oblikujejo prostorske sheme, osebnostne (čustva, motivacije) in socio-kulturne. Skupaj pa vplivajo na pretok informacij o okolju, kjer je treba upoštevati, da lahko posameznik hkrati sprejme le omejeno skupino potencialnih informacij o okolju, pa še to v glavnem le tiste, ki dopolnjujejo že oblikovano sliko ali zmanjšujejo negotovost in zahtevajo le manjše odzive.

Človek se na spremembe v okolju različno prilagaja ali nanje odgovarja, odvisno tudi od njegove okoljske ozaveščenosti. Percepcija okolja, problemov onesnaževanja ali pokrajinskih sprememb praviloma nikoli ne ustreza dejanskemu stanju. Vplivi oziroma informacije, ki prihajajo iz okolja, tudi onesnaženega, se modificirajo pri različnih skupinah ljudi, razlikujejo se tudi njihove predstave o okolju, kjer živijo, o njegovi kakovosti, onesnaženosti, vzrokih za njegovo degradiranost itd. Dejavniki, ki vplivajo na različno razumevanje, dojemanje okolja, ki modificirajo predstave o okolju pri različnih skupinah ljudi, so t.im. socialnogeografski filtri (Špes, 1998). So različno prepustni za vplive in informacije iz okolja ali o njem.

Pomen posameznega socialnogeografskega filtra ni univerzalen ali nespremenljiv, razlikuje se po območjih, na njegovo vlogo in pomen vplivajo razmere v družbi, raznovrstnost in obseg okoljskih problemov, dostop do informacij itd. Generalno pa »filtre«, ki vplivajo na bolj ali manj objektivno percepcijo okolja vidimo v naslednjih socialnogeografskih značilnostih:

- $\quad$ starostna sestava prebivalstva, kjer starost oziroma življenjski cikel praviloma vpliva na odnos do okolja, kamor sodi tudi odnos do škodljivih učinkov onesnaževanja. S starostjo sta povezana tudi obseg in vrsta izkušenj, pridobljenih in dojetih informacij, omogočene so primerjave za različne časovna obdobja, s stanjem v preteklosti itd.

- izobrazbena in poklicna sestava prebivalstva je eden najpomembnejših filtrov pri sprejemanju ali zavračanju informacij iz okolja. Pri poklicih gre predvsem za vprašanje povezanosti ali celo odvisnosti določenih skupin z dejavnostmi, ki sprožajo okoljske sprememb, in je zavračanje informacij pri njih praviloma večje. Pri izobrazbeni strukturi ugotavljamo, da manj izobražene skupine prebivalstva pogosteje zavračajo informacije o konkretnih negativnih učinkih onesnaževanja kot bolj izobražene, pogosteje kot slednje pa sprejemajo splošne informacije oziroma posplošene podobe ali mnenja o splošnejših ekoloških problemih.

- $\quad$ stopnja navezanosti in odvisnosti od narave, lastništvo zemlje, gozdov, živine... ponovno povzroča razlike v percepciji okolja. Prebivalci, katerih dejavnost je tesneje vezana na lastništvo naravnih virov, katerih delovni cikel je odvisen od naravnega, praviloma ne zavračajo informacij o raznovrstnih negativnih učinkih v okolju. V tem gre iskati tudi odgovor na vprašanje, zakaj so v Sloveniji sorazmerno zgodaj nastala razna ekološka gibanja in pobude ter predvsem opozorila neposredno prizadetih lastnikov gozdov o naraščajoči škodi, ki jo povzroča onesnaževanje okolja. To velja zlasti v primerjavi z drugimi, predvsem vzhodnoevropskimi državami s podobno družbeno ureditvijo, kjer pa je bila večina zemlje in gozdov podržavljena in so posamezniki izgubili občutek tesne soodvisnosti z naravo in čustvene navezanosti na zemljo. 
- kulturno, versko, nacionalno poreklo. Ta skupina kazalcev je sama po sebi verjetno manj prepoznavna in s poveličevanjem njihove vloge bi lahko zašli še na nevarno področje determinizma. $V$ povezavi z drugimi dejavniki pa prav gotovo vpliva tudi na sprejemanje in zavračanje informacij o okolju. Zanimiva je predvsem razlika v pojmovanju okolja, če na nekem območju nastane homogena skupina prebivalcev, katerih versko ali nacionalno poreklo se razlikuje od avtohtone večine. Večkrat se zgodi, da priseljenci, pomešani z domačini že skoraj v celoti prevzamejo vzorec obnašanja večine $v$ soseščini. Pod kulturno osnovo si predstavljamo tradicijo, navade, šege, vse tisto, kar ljudi postavlja v zgodovinski in razvojni okvir in od česar so večinoma odvisne njihove moralne norme.

- osebni motivi, čustva, politična usmeritev. Skupino teh kazalcev (filtrov) je najteže definirati, ker pri njej igra pomembno vlogo posebnost vsakega posameznika. Njihovo vlogo in pomen pri oblikovanju zaznave okolja je mogoče ugotavljati le z neposrednim anketiranjem vsakega posameznika.

Ne glede na učinke socialnogeografskih filtrov, se sprejeto, zaznano okolje vedno razlikuje od dejanskega. Od sprejemanja okolja, od stopnje razumevanja in prepoznavanja ekoloških problemov, skratka — od naše zaznave le-tega je odvisna tudi naša ekološka ozaveščenost, od tega so odvisne reakcije, obnašanje in predvsem odločitve, ki vodijo tudi do sprememb v okolju (Špes, 1998).

Med sprejetim okoljem in reakcijo pa ponovno nastopi druga skupina "filtrov", ki vplivajo na intenzivnost in obseg reakcij in ne nazadnje na ekološko zavest. To je skupina dejavnikov, ki so odraz splošnih družbenih razmer v nekem okolju. Najbolj zahtevni in najmanj prepustni so t. im. ekonomski "filtri", ki nastopijo praviloma takrat, ko ni opaziti takojšnjega učinka, ni merljivega dobička; upoštevati pa je treba, da naložbe v varovanje okolja praviloma ne dajejo kratkoročnih pozitivnih finančnih učinkov. Neugodno je tudi, če posameznik ali skupine ne sprejemajo odgovornosti za onesnaževanje okolja, niti nikakršnih finančnih obveznosti, kamor sodi tudi plačevanje ekoloških davkov, prištevanje stroškov okolja v končno ceno izdelka. Predvsem pa so »ekonomski filtri« ali pregrade najmočnejši v času recesije, gospodarske in socialne krize. Pri t.im. družbenih filtrih je zelo pomembna kvaliteta vzgoje in izobraževanja na okoljevarstvenem področju, prav tako pa tudi dostopnost do informacij in udeležba javnosti pri odločanju in vloga civilne družbe. Odvisni so tudi od nivojev sprejemanja odločitev za reševanje ekoloških problemov. V centraliziranih državah je pregrada večja kot v okoljih, kjer se tovrstni problemi rešujejo na lokalni ravneh. Politične pregrade se kažejo predvsem takrat, ko se teži k kratkoročnim učinkom (na primer pred volitvami) in se zanikajo ekološki problemi, katerih reševanje bi zahtevalo določene omejitve, rezultati pa bi se pokazali šele v prihodnosti, ko bi si uspehe lahko lastile druge politične skupine (Trudgill, 1990).

Na podlagi razumevanja in zaznavanja okolja in po premagovanju vseh naštetih pregrad (filtrov) se oblikujejo odnos do okolja in ekološka ozaveščenost. Posameznik ali skupina ljudi si pri odzivih na onesnaženo okolje postavi svojo prioriteto, ki pa ni nujno nastala na podlagi strokovnih ugotovitev, temveč je večinoma odraz njegove ozaveščenosti. Cifrić (1989) ugotavlja, da o ekološki zavesti ne moremo govoriti kot o statični kategoriji. Je namreč dinamična 
in se spreminja in prilagaja razmeram v določenem okolju, zgodovinskem procesu in stanju družbe. Njen nastanek in obseg nista pogojena z dejansko ogroženostjo okolja, temveč z odnosom družbe do okolja in naravnih virov.

Zanimiva je ugotovitev, da imamo ljudje pri prepoznavanju ekoloških problemov zelo "slab spomin". Ponavadi si zapomnimo dogodke iz štirih do petih let, kar si razlagajo z volilnimi ciklusi. Pred volitvami namreč skoraj vse stranke vključujejo v svoje programe napovedi o premagovanju ekoloških težav in nas s tem tudi opomnijo na večje okoljevarstvene probleme. Prav tako se ponavadi odzivamo na ekološke probleme, ki se dogajajo v naši neposredni bližini, le nekaj kilometrov stran ali kvečjemu nekaj deset kilometrov daleč, s prostorsko oddaljenosti slabi tudi naše zanimanje za tamkajšnje okoljske probleme. Bolj pa nas zanimajo globalni ekološki problemi, kot so ozonska luknja, kisli dež in splošno ogrevanje zemlje. Vendar zanimanje za globalne ekološke probleme praviloma ne vpliva na spremembe v vsakodnevnem obnašanju in razmišljanju, saj se posameznik ne čuti krivega za planetarne razsežnosti ekoloških problemov (Haber, 1993).

\section{RAZVOJ OKOLJSKE OZAVEŠČENOSTI V SLOVENIJI}

Zgodnja preverjanja ekološke ozaveščenosti so v 80. letih z vzorčnimi raziskavami posegala v najbolj degradirana območja Slovenije. Opozorila so na značilno dvojnost, kjer so imeli najbolj kritičen odnos do onesnaževanja okolja lastniki kmetijskih zemljišč in gozdov, veliko bolj tolerantni pa so bili meščani, predvsem anketirani, ki so bili posredno ali neposredno eksistenčno odvisni od industrijskih ali termoenergetskih obratov - pomembnih onesnaževalcev okolja. Prvo vseslovensko preverjanje ekološke ozaveščenosti je bilo leta 1990, ko so v projekt Slovensko javno mnenje vključili tudi posebne »ekološke« ankete. Takrat izraženo visoko stopnjo ekološke zavesti so razlagali z aktualnimi družbenimi razmerami, poveličevanjem pomena vsega kar je slovenskega in "visokega, skoraj mističnega odnosa do slovenske grude«. Na podlagi teh raziskav so se izoblikovale tri skupine prebivalcev: ekološko močno angažiranih, ki jih ekološki problemi močno prizadenejo, teh je bilo $11 \%$, največjo skupino so tvorili srednje angažirani (22\%), najmanjša pa je skupina ekološko pasivnih 2\%, drugi so bili neopredeljeni (Ekološke sondaže, 1993). Izkazalo se je, da sta razumevanje in poznavanje negativnih učinkov onesnaževanja ter ozaveščenost odvisna predvsem od izobrazbene stopnje, kakor tudi od onesnaženosti okolja anketiranih. Delovanje edine slovenske jedrske elektrarne je zbujalo strah med mlajšim prebivalstvom (kratek časovni odmik od černobilske katastrofe!). Po mnenju anketiranih pa je bila industrija glavni krivec za onesnaževanje okolja, sledijo ji termoelektrarne, manj pa so razmišljali o lastnem prispevku z ogrevanjem stanovanj in prometom.

Rezultati zadnjih javnomnenjskih raziskav (Politbarometer-FDV, 2005) pa že kažejo na višjo ekološko zavest, kar si razlagamo tudi z vedno boljšo dostopnostjo do informacij in udeležbo javnosti pri odločanju. Opazno je, da se med prebivalci povečuje zanimanje in zaskrbljenost nad izstopajočimi okoljskimi problemi. Med njimi posebej opozarjajo na onesnaženost voda ter uporabo kemikalij, sledijo ekstremni vremenski pojavi (suše, poplave, viharji) in siromašenje biotske pestrosti. Pogosteje kot v preteklosti opozarjajo na probleme 
povečanega onesnaževanja zraka zaradi naraščajočega prometa, zaskrbljeni pa so tudi zaradi nerešenega problema odlaganja radioaktivnih odpadkov iz jedrske elektrarne. Primerjava po posameznih starostnih skupinah prebivalstva pokaže, da so najmanjšo zaskrbljenost nad ekološkimi problemi izkazale mlajše starostne skupine (do 30 let), kar lahko razložimo z dejstvom, da so to skupine prebivalstva, ki rešujejo druge eksistenčne probleme. Manj okoljski problemi vznemirjajo tudi najstarejše skupine prebivalstva. Ponovno pa se je potrdila že znana ugotovitev, da se aktiven odnos do okolja in ekoloških problemov povečuje z zviševanjem izobrazbe anketiranih. Glede na to, da se ekološka zavest veča $\mathrm{z}$ višjo splošno izobrazbo, bi bilo treba ne le razširiti ekološko vzgojo in izobraževanje, ampak tudi raven splošne izobrazbe, ki bo omogočala širše razumevanje vzrokov in posledic onesnaževanja okolja.

Tudi raziskave o ekološki ozaveščenosti prebivalcev najbolj onesnaženih slovenskih mest so sredi prejšnjega desetletja (Špes, 1998) opozorile na vpliv posameznih socialnogeografskih kazalcev (filtrov) na percepcijo okolja in na njihove reakcije. Značilno je, da starejši prebivalci praviloma bolj prizanesljivo ocenjujejo kakovost bivalnega okolja in ga redkokdaj presojajo skrajno negativno ali skrajno pozitivno. V krajih, kjer se je onesnaževanje okolja v zadnjem desetletju zmanjšalo, so o tem prav tako pogosteje govorili starejši, kar je povezano s preteklimi izkušnjami in omogočeno primerjavo s stanjem pred sanacijami. Starejši tudi pogosteje omenjajo, da onesnažen zrak slabša njihovo počutje in zdravje. Izobrazbena in zaposlitvena sestava anketiranega prebivalstva je med vsemi demografskimi kazalci najmočneje vplivala na odnos do okolja. Bolj izobraženi so namreč realneje ocenjevali spremenjeno onesnaženost zraka, bodisi da se je ta zmanjšala ali povečala, in to ne le v njihovem bivalnem okolju, temveč tudi v celotnem imisijskem območju. Pogosteje kot manj izobraženi so opozarjali na prispevek lastnega onesnaževanja zraka (ogrevanje, promet) in večje je tudi njihovo zaupanje $\mathrm{v}$ delo strokovnjakov. Razlike v ekološki ozaveščenosti različno izobraženih skupin prebivalcev smo preverjali še z vprašanji o svetovnih ekoloških problemih, kjer se stopnja njihovega razumevanja prav tako veča $\mathrm{z}$ višjo izobrazbo. Najbolj jasna razlika pri iskanju krivca za onesnaženo okolje se kaže med zaposlenimi v tovarnah, ki onesnažujejo okolje, in drugimi prebivalci. Prvi so namreč praviloma opozarjali na neindustrijske vire emisij, drugi pa na industrijske. $Z$ višjo izobrazbo prebivalcev se torej povečuje razumevanje vzrokov in posledic onesnaževanja okolja, odnos do degradiranega okolja je bolj kritičen, ekološka zavest višja, vzporedno pa tudi načrti in želje po spremembah bolj realni. Boljša ekološka ozaveščenost pa sproža tudi večje pritiske na glavne onesnaževalce glede ekoloških sanacij, boljše je tudi razumevanje pozitivnih učinkov uporabe okolju prijaznih naprav.

Značilna je še razlika v ocenjevanju negativnih okoljskih vplivov med prebivalci najbolj onesnaženih in manj onesnaženih krajev. V slabšem okolju so prebivalci pokazali bolj prizanesljiv odnos do okolja, ker so se nanj sčasoma "navadili", v čistejšem pa so prebivalci zahtevnejši in bolj kritični do vsakega, čeprav manjšega onesnaževanja okolja, in odločneje terjajo izboljšave. Gre za navidezno nasprotje, ki pa je odraz njihove percepcije okoljskih problemov in zavesti ter odnosa prebivalcev do lastnega okolja.

Predhodno ugotovitev, da ekološka ozaveščenost ni statična, kakor tudi ne odzivi na prepoznane okoljevarstvene probleme, ampak se spreminja in narašča tudi s kvaliteto in obsegom informacij, lahko nazorno ilustriramo s primerom iz Zasavja. V tem imisijskem 
območju se v zadnjem času zelo krepijo skupine pritiska, ki opozarjajo na onesnaževanje ozračja z emisijami iz trboveljske cementarne. Njihova opozorila niso namenjena le domačemu prebivalstvu in slovenski javnosti, ampak se širijo tudi preko državne meje. Nekatere predhodne raziskave (Špes, 1998) pa so nakazale zanimivo posebnost, da so bili prav Trboveljčani razmeroma strpni pri ocenjevanju kvalitete njihovega življenjskega okolja, češ da ni prekomerno onesnaženo ali le zmerno, kar je bila veliko ugodnejša ocena kakor pri prebivalcih drugih slovenskih onesnaženih mest. Pred desetimi leti, ko so bili aktualni načrti za gradnjo nove trboveljske termoelektrarne, je to precej vznemirilo slovensko javnost in posamezne skupine civilne družbe iz drugih slovenskih krajev, ki so dosegli, da smo se na referendumu odločali o tem projektu. Značilno pa je, da je takrat načrtovana gradnja doživela zelo pasiven odnos med domačini. To je pokazala tudi raziskava (Špes, 1997), s katero smo želeli proučiti, kakšen je odnos prebivalcev Trbovelj do načrtovane gradnje TET3. Domala tri četrtine anketiranih je soglašala z gradnjo termoelektrarne, nasprotovala pa ji je le desetina. Nadaljnja analiza teh odgovorov je opozorila, da se je negativen odnos do gradnje pogosteje pojavljal med mlajšimi prebivalci, med njimi se več kot tretjina ni strinjala z gradnjo TET3 oziroma z nadaljevanjem energetske dejavnosti v Trbovljah, pri višjih starostnih skupinah pa se je ta delež hitro zmanjševal. Odnos do načrtovane gradnje se je spreminjal tudi med različno izobraženimi prebivalci Trbovelj in se je presenetljivo (ali pa tudi ne, saj so napovedovali gradnjo okolju bolj prijazne termoelektrarne!) z višjo izobrazbo zmanjševal negativen odnos. Presenetil pa je velik delež neopredeljenih prav v najvišji izobrazbeni skupini anketiranih prebivalcev. Med anketiranimi, ki so bili zaposleni v termoelektrarni ali v premogovniku, ni bilo niti enega odgovora, da se z gradnjo nove termoelektrarne ne bi strinjali ali, da jim je vseeno. Tudi anketirani iz gospodinjstev, kjer je bil kdo od družinskih članov zaposlen v energetsko-rudarski dejavnosti, so skoraj brez izjeme soglašali s projektom. Polovica anketiranih je svoje strinjanje opravičevala s pričakovanimi ekološkimi izboljšavami, skoraj tretjina pa je menila, da tega ne pričakujejo, so pa najpomembnejši ekonomski učinki oziroma podaljšana možnost zaposlovanja v premogovniku. Kljub odgovorom, ki niso bili skladni s pričakovanji in so kazali na takratno relativno nizko ekološko ozaveščenost prebivalcev Trbovelj, je v luči kasnejših dogajanj zanimivo, da je kar $80 \%$ anketiranih predlagalo, da je potrebno izboljšati pravočasnost in obseg ter strokovno korektnost obveščanja javnosti o okoljskih zadevah in jih predhodno seznaniti z načrtovanimi posegi.

\section{SODELOVANJE JAVNOSTI PRI ODLOČANJU O OKOLJSKIH POSEGIH}

Pri izvajanju trajnostnega razvoja je ključno sodelovanje javnosti. Uravnoteženost ekonomskih, socialnih in okoljskih ciljev v strategijah trajnostnega razvoja zahteva namreč družbeni konsenz. Zato je pomembno vključevanje posameznikov in različnih interesnih skupin pri oblikovanju odločitev, kar pa zahteva celovito in pravočasno obveščanje. Največji napredek na tem področju je prinesla aarhuška konvencija, ki zapoveduje participacijo javnosti na področju okoljevarstvene politike. 
Spodbujanje javne zavesti in sodelovanje javnosti z dostopnostjo informacij o okolju je eno temeljnih načel, ki je bilo zapisano že v deklaracije o okolju in razvoju iz Ria, ključne podlage za udejanjanje teh načel pa pomeni sprejetje omenjene konvencije, ki jo je, skupaj s 35 državami in EU, 15. junija 1998 podpisala tudi Slovenija na 4. ministrski konferenci Okolje za Evropo v Aarhusu na Danskem.

Aarhuška konvencija, ki temelji na izhodiščih trajnostnega razvoja, uveljavlja:

- pravico do obveščenosti o kakovosti okolja in okoljskih vplivih - prost dostop do okoljskih informacij;

- pravico do sodelovanja pri okoljskem odločanju-sodelovanje javnosti;

- pravico do pravnih sredstev za zaščito pravic civilne družbe - dostop do pravnega varstva.

Civilni družbi priznava poseben družbeni pomen in nalaga državam, da zagotovijo krepitev možnosti nevladnega sektorja tako, da podpirajo okoljsko ozaveščanje in izobraževanje širše javnosti.

Pri obveščenosti o okolju upošteva konvencija pravico dostopa do okoljskih informacij na lastno zahtevo in na podlagi javno dostopnih informacij, ki jih ustrezne službe posredujejo javnosti. Predlaga, kje je potrebno vzpostaviti sistem poročanja in razširjanje informacij v javnost. Posebno pozornost posveča obveščanju javnosti ob neposredni nevarnosti za zdravje ljudi ali za okolje v primeru ekoloških nesreč ali preseganju mejnih vrednosti onesnaženja. Zahteva tudi obveščenost potrošnikov o izdelkih in uvaja registre onesnaževanja, ki so javno dostopni.

Drugi del konvencije, ki govori o udeležbi javnosti, predvideva možnosti njihovega sodelovanja pri sprejemanju odločitev o dovoljenjih za konkretne posege v okolje, sodelovanje pri sprejemanju načrtov in programov v zvezi z okoljem in sodelovanje pri pripravi predpisov, zakonov in drugih obvezujočih dokumentov (Aarhuška konvencija v Sloveniji, 2002).

Kljub jasnim izhodiščem konvencije in njihovi vključenosti v našo zakonodajo ter $v$ nacionalni program varstva okolja, se v praksi še vedno pojavljajo težave in napake pri komunikaciji med javnostjo in različnimi institucijami. Še vedno so primeri, ko je javnost vključena prepozno, kar povzroči pri ljudeh občutek prevaranosti in nemoči. Težava nastopi tudi, če ni predlagana alternativa in zato se hitro oblikuje opozicija proti edinemu predlogu. Takšnih primerov je bilo v zadnjem času največ pri iskanju ustreznih lokacij za centralna regijska odlagališča odpadkov.

Najbolj svežje kranjski primer odlagališča odpadkov Tenetiše, kamor so dnevno odvažali okoli 100 ton odpadkov. Oktobra 2007 je odlagališču poteklo obratovalno dovoljenja, zato so začeli odpadke odvažati na druge deponije (največ na Malo Mežaklo). Po občinskih načrtih naj bi na obstoječi lokaciji postavili novi regijski center za ravnanje z odpadki, enega od 12-ih v Sloveniji. Temu so se uprli prebivalci sosednjih naselij Mlaka in Tenetiše in zato je postopek gradnje regijskega centra zaustavljen, po uspešni mediaciji pa je bilo ob koncu februarja 2008 sklenjeno, da na tej lokaciji ne bodo gradili novega odlagališča odpadkov. Zanimiv je podatek, da je na predhodnem posvetovalnem referendumu kar 85\% prebivalcev kranjske občine podprlo gradnjo centra, med prebivalci bližnjih naselij pa le polovica. Predstavniki civilne iniciative, ki so nasprotovali odlagališču, so opozarjali na napake pri načrtovanju centra, ko občina prebivalcev ni pravočasno obvestila o gradnji. To so storili šele po tem, ko so 
se o gradnji že odločili na mestnem svetu. Prihaja pa še do različnih pogledov na to, kdo naj bo o gradnji centra vprašan: vsi prebivalci kranjske občine ali le prebivalci Mlake in Tenetiš. Zaradi pomanjkljivega obveščanja javnosti in dostopnosti do informacij je med prebivalci prisoten še dvom o nepristranskosti in strokovnosti inšpekcijskih služb (Bavdek, 2007).

Velik izziv za preverjanje, kako se upoštevajo načela javne participacije v praksi, je bilo tudi vključevanje javnosti in nevladnih organizacij pri iskanju lokacij za odlagališče nizko radioaktivnih odpadkov v Sloveniji. Zaradi preteklih težav ter nedomišljenega in improviziranega postopka in posledično odklonilnega odnosa prizadetega prebivalstva, so pri zadnjem iskanju ustreznih lokacij že na začetku postopek vodili javno. Pomembno izhodišče pri presoji alternativnih lokacij za takšen objekt je, poleg upoštevanja vseh strokovnih vidikov, tudi družbena sprejemljivost. Slednjega so skušali doseči s transparentnostjo vseh faz izbora, odprtostjo za različne javnosti in omogočanje njihovega soodločanja ter upoštevanje družbenih značilnosti "prizadetih« območij. Odločili so se za kombinirani postopek, ki združuje elemente tehničnega vrednotenja in prostovoljnega pristopa občin in lokalnih skupnosti. Leta 2002 je bil javno objavljena karta potencialno primernih območij za odlagališče, dve leti kasneje pa so bile vse občine povabljene, da sodelujejo pri iskanju primerne lokacije. Prijava občine, da se vključi v širši izbor, še ni bila obvezujoča, omogočila pa je prve terenske raziskave in monitoring. Podrobnejše raziskave pa so nato nadaljevali v občinah, kjer so predhodne raziskave pokazale na potencialno najbolj ustrezne lokacije. V končnem izboru je ostalo pet občin (Medmrežje, 1). Kljub transparentnem postopku izbire lokacij, so občine same naredile še vedno nekaj napak. Občanom bi morale posredovati več informacij o zagotavljanju njihove varnosti, nekatere pa so v postopek premalo vključevale nevladne organizacije oziroma so bile te premalo aktivne.

Nasploh ugotavljamo, da lahko le pravočasno informiranje in vključevanje javnosti in lokalnih skupnosti prepreči ali vsaj omili NIMBY efekti in nezaupanje v delo strokovnjakov ali investitorjev določenega projekta. Ni dovolj upoštevati zgolj strokovne in tehnične vidike izgradnje objektov, ampak tudi socialnogeografske oziroma percepcijo okoljevarstvenih problemov in okoljsko zavest, ki so pri izbiri lokacije prav tako pomembni.

Med pokazatelje splošne okoljske zavesti sodi tudi delovanje nevladnih organizacij, ki so del organizirane javnosti. Civilni družbi, še posebej nevladnim organizacijam kot aktivnim zagovornikom okolja, priznava aarhuška konvencija poseben pomen. V Sloveniji danes na področju varstva okolja deluje okoli 140 nevladnih organizacij (Medmrežje, 2). Nastajati so začele po letu 1993, ko se je veliko prejšnjih okoljevarstvenih in sorodnih društev preoblikovalo v nevladne organizacije. Na področju varstva okolja največkrat zbirajo in posredujejo informacije, prirejajo delavnice, seminarje, posvete, opravljajo raziskave, skrbijo za sanacijo nelegalnih odlagališč odpadkov itd. S svojim delovanjem vplivajo posredno še na oblikovanje okoljske politike in zakonodaje, predvsem pa na ozaveščanje javnosti. Nekatere delujejo zgolj v lokalnih okvirih, druge imajo širši nacionalni pomen; nekatere združujejo člane na podlagi aktivizma, druge na strokovni stanovski pripadnosti.

Z vstopom v EU se je položaj nevladnih organizacij še izboljšal, povečuje se tudi njihovo sodelovanje pri odločanju o okoljskih problemih. (Medmrežje, 4). Slovenska resolucija o nacionalnem programu varstva okolja do leta 2012 vidi pomen nevladnih organizacij predvsem $\mathrm{v}$ promociji varstva okolja in povečevanju ozaveščenosti, izobraževanju, v strokovni pomoči 
(pripravi strokovnih podlag, mnenj), nadzoru, sodelovanju pri upravljanju z zavarovanimi območju itd.

\section{ZAKLJUČEK}

Skrb za nenehno povečevanje okoljske ozaveščenosti in dostop do okoljskih informacij sodita med temeljna načela trajnostnega razvoja, saj zagotavljata objektivno in strokovno sodelovanje javnosti pri iskanju uravnoteženosti med ekonomskimi, socialnimi in okoljskimi cilji. Ugotavljamo, da je javnost relativno dobro okoljsko ozaveščena, a je potreben vzpon okoljske odzivnosti in razširitev na področje osebne odgovornosti in spremenjenih življenjskih vzorcev, ki bodo težili k zmanjšanemu obremenjevanju okolja. Ker je percepcija okoljskih sprememb in ekoloških problemov bolj ali manj odvisna od vrste »socialnogeografskih filtrov« (starostnih, izobrazbenih, poklicnih....) in, ker so empirične raziskave pokazale, da sta izobrazba in ekonomska moč prebivalstva med najpomembnejšimi, se kaže potreba po razširitvi ne le ekološke vzgoje in izobraževanje, ampak tudi raven splošne izobrazbe, ki bo omogočala širše razumevanje vzrokov in posledic ekoloških problemov. Z višjo izobrazbo prebivalcev se ne krepita zgolj ekološka zavest in prepoznavanje pravih ekoloških problemov v njihovem bivalnem ali v globalnem pogledu, ampak je pri njih tudi največ pobud za ekološke izboljšave.

Za Slovenijo na splošno velja relativno dobra deklarativna ekološka ozaveščenost, bolj problematičen pa je velik razkorak z okoljskim ravnanjem in relativno slabim dejanskim okoljskim obnašanjem. Največja težava nastopi v primeru, ko prebivalci najbolj onesnaženih območij slabo prepoznavajo glavne vire onesnaževanja okolja in so bolj nagnjeni k iskanju krivcev drugje, ne prepoznajo pa lastne krivde in zato niso pripravljeni ukrepati in spremeniti svoje delovanje in obnašanje. Zato je ena od ključnih nalog »trajnostne družbe«, da omogoča dostop do objektivnih informacij in zagotavlja udeležbo javnosti pri odločanju in s tem pomaga spreminjati tudi vzorce navad, ki imajo negativne vplive na okolje.

\section{Viri in literatura}

Aarhuška konvencija v Sloveniji, 2002: Strokovna priporočila za implementacijo konvencije o dostopu informacij, udeležbi javnosti pri odločanju in dostopu do pravnega varstva $\mathrm{V}$ okoljskih zadevah. Zbornik, REC za Srednjo in Vzhodno Evropo, Ljubljana.

Agenda 21 za Slovenijo, 1995, Umanotera, Slovenska fundacija za trajnostni razvoj, Ljubljana, s. 6

Bavdek, M., 2007: Aarhuška konvencija. Pravna fakulteta Univerze v Ljubljani, seminarska naloga, Ljubljana, s. 9.

Brimblecombe, P., Nicholas, F.M,. 1993: Case Study: History and Ethics of Clean Air. In: Environnmental Dillemas, Ethics and Decisions, edited by R.J. Berry, Chapman \& Hall, London, s. 150-187.

Cifrić, I. 1989: Socijalna ekologija. Prilozi zasnivanja discipline. Globus, Zagreb

Ekološke sondaže, 1993: Dokumenti Slovenskega javnega mnenja, urednik Niko Toš, FDV - IDV, Center za raziskovanje javnega mnenja in množičnih komunikacij, Ljubljana. 
Gold, R.J. 1980: An Introduction to Behavior Geography. Oxford University Press, Oxford

Haber, W. 1993: Environmental Attitudes in Germany: the Transfer of Scientific Information into Political Action. In.: Environmental Dillemas, Ethics and Decisions, edited by R.J. Berry, Chapman \& Hall, London, s.56.

Kirn, A., 2003: Ekološka/okoljska zavest Slovencev na pragu tretjega tisočletja. Teorija in praksa, let 40/1, Ljubljana, str. 25.

Knox, P. 1987: Urban Social Geography. Longman Scientific \& Tehnical, London, s. 189.

Medmrežje 1: http//www.sigov.si/arao

Medmrežje 2: http//www.rec-lj.si/

Medmrežje 3: http//www.cnovs.si/

Ministrstvo za okolje in prostor (MOP), 2005: Resolucija o nacionalnem programu varstva okolja, Ljubljana.

Ministrstvo za okolje in prostor (MOP), Uprava za varstvo narave, 1998: Nacionalni program varstva okolja, Ljubljana.

Orožen, J. 1974: Zgodovina Celja in okolice, II. Del. Celjski zbornik, posebna izdaja, Celje, s354.

Our Common Future, 1987: WCED,Oxford University Press, Oxford, s. 46.

Politbarometer 1/2005: Javnomnenske raziskave o odnosu javnosti do aktualnih razmer in dogajanj v Sloveniji. Fakulteta za družbene vede Univerze v Ljubljani, Inštitut za družbene vede, Center za raziskavo javnega mnenja, Ljubljana.

Slovenija 88. Okolje in razvoj, 1998: SAZU-Svet za proučevanje in varstvo okolja, Zbornik, Ljubljana

Špes, M., 1997: Poročilo o vplivih na okolje ob izgradnji nadomestnega objekta TET3. Psihosocialni vidik, elaborat, Inštitut za geografijo, Ljubljana.

Špes, M., 1998: Degradacija okolja kot dejavnik diferenciacije urbane pokrajine. Geographica Slovenica 30, Ljubljana, s. 9-20.

Trudgill, T.S. 1990: Barriers to a Better Environment. What stops us solving enviromental problems? Belhaven Press, a division of Pinter Publishers, London.

Zakon o varstvu okolja, 1993, Ur.l. RS, št. 32/93.

Zakon o varstvu okolja, 2004, Ur.l. RS št, 31/04.

Zelena knjiga o ogroženosti okolja v Sloveniji , 1972: Prirodoslovno društvo Slovenije, Ljubljana.

\section{THE IMPORTANCE OF ENVIRONMENTAL AWARENESS AND PUBLIC PARTICIPATION FOR SUSTAINABLE DEVELOPMENT}

\section{Summary}

Of key importance in the implementation of sustainable development is also the participation of the public in the broadest sense. As a rule, people form their attitude towards the environment and respond to negative consequences of their own activities on the basis of their comprehension and insight, i.e., their perception of the accepted environment. Thus, they appear in a double role: one the one hand, they occur as the cause of the majority of negative changes in the environment, and on the other, as receptors of these changes and their resul- 
tant negative consequences. Besides the direct impacts of the changed environment there are also indirect impacts which are manifested in the acceptance or comprehension of the causes and results of pollution, in short, in the ecological awareness and in the reactions. It has been established that perception of environmental changes and ecological problems is subject to bigger or lesser transformations in different socio-geographical groups of inhabitants, in the so-called socio-geographical filtres (related to age; educational; vocational; etc). Empirical studies have shown that education and economic power of the population rank among the most important filters. Higher education of the population radically enhances their ecological awareness and improves the identification of true ecological problems both in their own living environment and in the global sense, so that they also make the majority of motions of how to improve the environment. This exposes the necessity not only of extending the ecological education, but also of raising the level of general education, which will, consequently, enable more complex comprehension of the causes and the consequences of environmental pollution. The ecological awareness exerts influence on the quality and quantity of people's reactions in the environment.

Relatively early responses to and warnings against the increasing occurrence of environmental pollution have been established for Slovenia (e.g. the Green Book on the State of Environment was published in the year when the First World Conference on the Environment took place). And the general ecological awareness has significantly increased since the early measurements performed in the 1980s, when it was rather low and under the strong influence of different factors (filters). However, more problematic seems to be the great discrepancy between the rather high environmental awareness or high declarative willingness for environmental attitude and the rather poor factual environmental attitude. The greatest difficulties occur when the inhabitants of the most heavily polluted areas poorly recognize the main sources of environmental pollution and are more prone to seek for culprits elsewhere, and they are not able to recognize their own responsibility and therefore are not willing to take any steps or change their activities or behaviour. The awareness of one's own participation in the generation of environmental consequences is the basic prerequisite that people change their patterns of behaviour, and it is absolutely necessary that the scope of personal responsibility be increased.

Though we have established that the public is rather well informed about the environmental issues, an enormous shift will have to take place in the field of environmental responsiveness. Therefore, one of the key tasks of »sustainable society« is to enable the access to objective information and grant the participation of the public in taking decisions, thus also helping to change the patterns of behaviour which exert negative influence on the environment.

For a qualitative and constructive participation of the public in environmental decision taking it is of great importance to include the public in time in decision taking processes. Consistent observing of these principles, defined in the Aarhus Convention, also renders possible that negative responses by the public or local community can be avoided while planning the interventions, and thus the NIMBY effect as well. Important in the field of public participation in taking the decisions related to the environment is also the existence and the activities of environmental protection movements, which can certainly raise the interest in environmental issues and thus contribute to the intensification of public responses. 